\title{
Medical Education and Duty Hours: Do We Really Care?
}

Peter G. Brindley MD

\begin{abstract}
About the Author
Peter Brindley MD is a full-time clinical intensive care physician. He works in the General Systems Intensive Care Unit and NeuroSciences Intensive Care Unit of the University of Alberta Hospital, Edmonton, Canada. He is a Professor of Critical Care Medicine and Adjunct Professor of Anesthesiology and Adjunct Professor of Medical Ethics.
\end{abstract}

$\mathrm{T}$ he Canadian Society of Internal Medicine has a noble mission statement that bears repeating. The goal is to "go beyond simple transmission of information, and to make a lasting impact on the knowledge, skills and attitudes of clinicians and future clinicians; to narrow the theory-to-practice gap; to improve the health of our patients and of all Canadians." I agree wholeheartedly; in fact, I presume we all agree. How could you not? But the devil is always in the details. What does this really mean for how we prepare future doctors? More contentiously, what does this mean for duty hours? This (reactionary?) author believes it is worth routinely examining whether we live up to our lofty mission. If not, then we should accept a few inconvenient truths.

Workloads are not decreasing, but resident duty hours clearly are. Diminished resident hours means more routine clinical work done by fewer, more senior, and more expensive staff. Strangely, few cry foul over the fact that these "seniors" have less time to recuperate, manage their health, maintain their learning, promote quality control, or otherwise advance their field. In an increasingly stressed system, we should not be surprised if formal education becomes the first victim; next is the "luxury" of informal learning, followed by the working relationship between educators and trainees. In short, there are fewer staff members available to teach and fewer learners to receive their teachings. In what way is this beneficial to learners, let alone patients?

Even more concerning to this physician is that studies suggest that despite reduced trainee hours, errors are not decreasing, and time off is not being used for reading or writing. Trainees are not allowed to remain post-call as learners, nor do they stay to teach (each other, the nurses, or their students). In short, reduced on-call hours have not been shown to offer measurable benefits to patients. When I have fewer clinical hours, I increase my reading, writing, and reviewing (even if I exceed duty hours). This is because I have the privilege of a respected profession, coupled with the responsibility for vulnerable patients. That may sound atavistic, even quaint. But to return to that old medical litmus test: "What would your mother want?"

Others retort that they want their doctor to be rested, and reduced work hours clearly means fewer errors. However, not so fast. Less fatigue is associated with fewer errors, but the benefit is limited to that solo practitioner at that specific time; medical errors do not appear to lessen either overall or for individual patients. This is because errors are transferred to those practitioners who remain. In addition, errors may increase with increased sign-over (aka sign-off or hand-over) from one practitioner (or team) to another. Errors may increase because "juniors" attain less volume-based competence (i.e., weaker "clinical reflexes"). Moreover, those juniors remain junior (at least in skill set) for longer; they commit their errors at a more senior level and with less supervision. If reduced trainee duty hours were a drug, I doubt it would get Health Canada approval.

If trainees are doing less but we award the same qualifications, then simple mathematics shows that residencies need to be lengthened. Notably, few have called for this. Instead, competency-based training and simulation are enthusiastically promoted, although less enthusiastically funded. Both may play an important role, but they are not panaceas. After all, coupled with reduced hours, we should admit (and I would suggest we admit it to the public) that nowadays almost no trainee is 
actually failed. Therefore, declaring competency means nothing if you cannot be declared otherwise. "Incomplete" trainees (we've even lost the courage to use the word "failed") are blamed on inadequate efforts (or inadequate documentation) by their supervisors, strangely not on the individuals themselves. While seasoned practitioners are quite rightly expected to be responsible for their own education and outcomes, this responsibility is now de-emphasized in training. Accordingly, this (curmudgeon) physician is nervous for the future.

Patients need clinical decision making that is bespoke and compassionate. This requires experience and wisdom, which in turn come from following many patients through many illnesses. Reduced hours can mean that decisions are avoided, consults are increased, and more tests are ordered, even though unnecessary and harmful. All of this affects efficiency, throughput, cost, and safety. Reduced hours also decrease "patient ownership" and threaten generalism. Fragmented care ("I look after only the bowel lumen, not the whole gut") is one thing, but more concerning is end-of-life decision making. Eighty percent of Canadians die in hospital but rarely because nothing more can be done. Instead, a decision is required (and before patients become moribund) $-\mathrm{a}$ decision that the patient's dignity, comfort, and wishes are better served by palliative care, not escalation. In short, patient-focused care requires your presence and experience. I wish it were otherwise (I also have a home life), but wishing will not make it so.

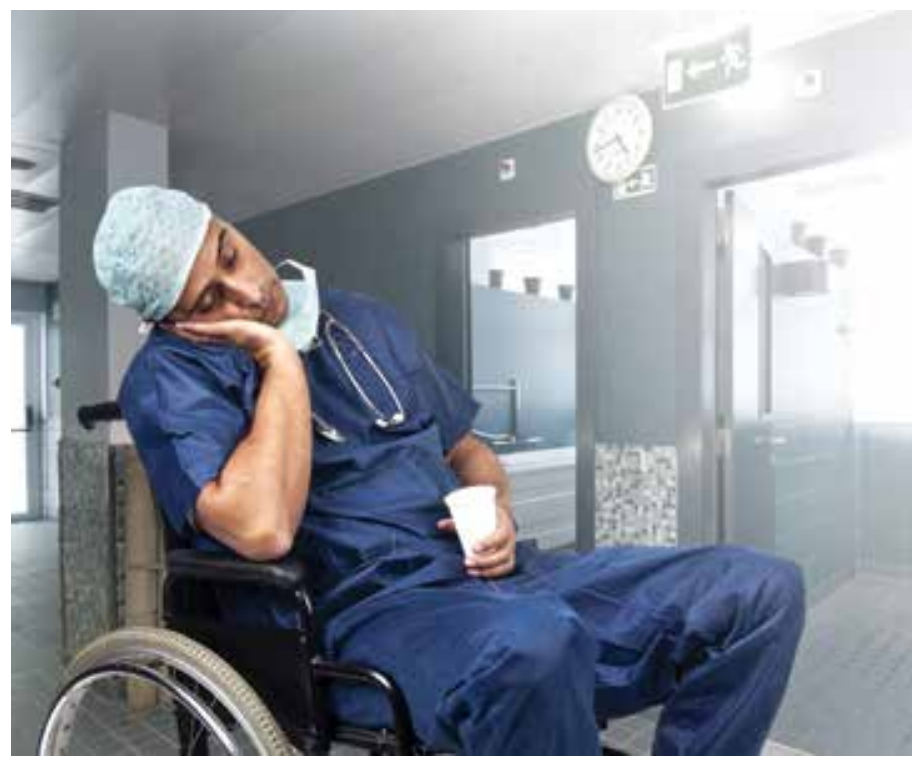

The journey from "I don't do it" to "therefore, I can't do it" to "therefore, I won't learn it" is perilously short. You may not forget how to ride a bicycle, but you can forget how to manage a complex patient or how to talk with families. However, with reduced hours, trainees might never learn to ride that bike. Moreover, if you believe (as my teachers taught me) that "education is what is left after you have forgotten what you were taught," then we must accept the idea that trainees need to learn more than just facts. The hospital is where you learn attitudes, behaviours, and adaptability, as well as how to work with others. Only at the bedside do you learn that a "team of experts"
"The hospital is where you learn attitudes, behaviours, and adaptability, as well as how to work with others." is not an "expert team"

and experience the perils of the "ninja consult" (notes hidden in a chart but nothing communicated) and the dangers of the "opaque consult" (no clear plan; just a repeat of the history, followed by those noncommittal words, "will review with staff”).

Presumably, the goal is for trainees to become-and for educators to help produce-graduates "fit for task" (i.e., competent and capable) as well as "fit for life" (i.e., balanced and psychologically resilient). Whether I liked or understood it, I attained competence by completing my "ten thousand hours" and following unambiguous feedback. I heard that "10\% more effort can make you appear 50\% better" and that getting hired is about "the three A's": availability, affability, and ability, in that order. I heard these things not because I was special but because I was there. I graduated from the University of British Columbia, whose motto, Tuum Est, means that your education is ultimately "up to you." To update this motto, I would suggest it is "up to us." This includes ensuring that our methods match our mission.

Peter G. Brindley MD

Associate Editor 